\title{
Stability of Woodchips Biochar and Impact on Soil Carbon Stocks: Results from a Two-Year Field Experiment
}

\author{
Irene Criscuoli ${ }^{1,2, *}$, Maurizio Ventura ${ }^{2}{ }^{\circ}$, Katja Wiedner $^{3}$, Bruno Glaser ${ }^{3} \oplus$, Pietro Panzacchi ${ }^{2,4}{ }^{\oplus}$, \\ Christian Ceccon ${ }^{2}$, Maximilian Loesch ${ }^{5}$, Barbara Raifer ${ }^{5}$ and Giustino Tonon ${ }^{2,+}$ \\ 1 Consiglio per la Ricerca in Agricoltura e L'analisi Dell'economia Agraria CREA (Council for Agricultural \\ Research and Economics), Centro di Ricerca Agricoltura e Ambiente (Research Centre for Agriculture and \\ Environment), Via di Lanciola, 12/a, 50125 Firenze, FI, Italy \\ 2 Faculty of Science and Technology, Free University of Bozen, Piazza Università, 5, 39100 Bolzano, BZ, Italy; \\ maurizio.ventura@unibz.it (M.V.); pietro.panzacchi@gmail.com (P.P.); christian.ceccon@unibz.it (C.C.); \\ giustino.tonon@unibz.it (G.T.) \\ 3 Faculty of Natural Sciences III, Institute of Agricultural and Nutritional Sciences, Soil Biogeochemistry, \\ Martin Luther University Halle-Wittenberg, Von-Seckendorf-Platz 3, 06120 Halle, Germany; \\ wiedner@kompost-ost.de (K.W.); bruno.glaser@landw.uni-halle.de (B.G.) \\ 4 Dipartimento di Bioscienze e Territorio, Università Degli Studi del Molise, 86090 Pesche, IS, Italy \\ 5 Laimburg Research Center, Laimburg 6, I-39051 Pfatten, BZ, Italy; maximilian.loesch@provincia.bz.it (M.L.); \\ barbara.raifer@laimburg.it (B.R.) \\ * Correspondence: irene.criscuoli@crea.gov.it \\ + Prof. Giustino Tonon is co-authors, but he recently died.
}

Citation: Criscuoli, I.; Ventura, M.; Wiedner, K.; Glaser, B.; Panzacchi, P.; Ceccon, C.; Loesch, M.; Raifer, B.; Tonon, G. Stability of Woodchips Biochar and Impact on Soil Carbon Stocks: Results from a Two-Year Field Experiment. Forests 2021, 12, 1350. https://doi.org/10.3390/f12101350

Academic Editor: Christopher Gough

Received: 24 August 2021

Accepted: 28 September 2021

Published: 2 October 2021

Publisher's Note: MDPI stays neutral with regard to jurisdictional claims in published maps and institutional affiliations.

\section{Copyright: (C) 2021 by the authors.} Licensee MDPI, Basel, Switzerland. This article is an open access article distributed under the terms and conditions of the Creative Commons Attribution (CC BY) license (https:// creativecommons.org/licenses/by/ $4.0 /)$.

\begin{abstract}
Biochar has been shown to improve soil quality and crop yields. Furthermore, thanks to its high carbon content $(C)$ and stable chemical structure, biochar can sequester $C$ in the soil for a long time, mitigating climate change. However, the variability in published biochar stability in the soil makes verifying this trait under different environmental and agricultural conditions necessary. Moreover, most of the published literature refers to short-term incubation experiments, which are considered to not adequately represent long-term dynamics under field conditions. This article reports the results of a field experiment carried out in a vineyard near Merano, northern Italy, where the stability of woodchips biochar in soil, its impact on the total soil C stocks as well as on the original soil organic C (priming effect) were studied over two years. Vineyard soil (Dystric Eutrochrept) was amended with biochar ( 25 and $50 \mathrm{t} \mathrm{ha}^{-1}$ ) alone or together with compost ( $45 \mathrm{t} \mathrm{ha}^{-1}$ ) and compared with unamended control soil. Two methods assessed the stability of biochar in soil: the isotopic mass balance approach and the quantification of Benzene PolyCarboxylic Acids (BPCAs), molecular markers of biochar. The amount of $C$ in the soil organic matter (SOM-C) was determined in the amended plots by subtracting the amount of biochar- $\mathrm{C}$ from the total soil organic $\mathrm{C}$ stock, and the occurrence of priming effect was verified by comparing SOM-C values at the beginning and at the end of the experiment. Results did not show any significant biochar degradation for both application rates, but results were characterized by a high variation. The application of $50 \mathrm{t} \mathrm{ha}^{-1}$ of biochar significantly increased soil C stock while no effect of biochar on the degradation of SOM-C was observed. Results were confirmed in the case of biochar application together with compost. It can be concluded that the use of woodchips biochar as a soil amendment can increase soil C content in the medium term. However, further analyses are recommended to evaluate the impact of biochar on climate change mitigation in the long term.
\end{abstract}

Keywords: biochar; stability; priming effect; soil C stocks; compost; isotopes; BPCA; vineyard

\section{Introduction}

Biochar has been studied by the scientific community for the past 20 years, owing to its potential use as a soil conditioner in agriculture [1-3]). If added to the soil, biochar can 
improve its chemical [4], physical [5], and biological [6,7] characteristics, contributing to increasing agricultural yields [1,8] and reducing nutrient losses from soil.

Another positive impact of biochar is its potential contribution to increasing the carbon (C) sequestration capacity of the soil [2,9-11]. In fact, given its aromatic chemical structure, biochar is difficult to degrade by soil microorganisms. However, biochar stability is affected by several factors such as the feedstock used, the production conditions, the environmental framework and the study design [12]. For these reasons, previous studies on biochar stability have provided conflicting results [13]. Furthermore, most of these studies have been performed in the laboratory, which are not representative of field conditions [14], and field studies often have a limited duration, even though it is well-known that the estimation of biochar stability is affected by experimental duration [11].

Furthermore, studies on perennial tree crops are still scarce [6,15] mainly because of the long time needed to observe relevant effects in plants with a largely developed root system and the difficulties in performing trials in controlled conditions [16]. However, biochar has been shown to have potential advantages in terms of increased productivity and an improved plant-water relation in vineyards [16,17].

Another key factor affecting biochar-C sequestration potential is its interaction with soil organic matter (SOM) [18]. Biochar can stimulate SOM degradation (positive priming effect), partially offsetting its $C$ sequestration potential, or protect SOM from degradation (negative priming effect), further increasing soil $\mathrm{C}$ sequestration after biochar application $[19,20]$. Also, in this case, several factors such as the experimental duration can affect the direction and the extent of the priming effect [21,22]. However, most of the studies on the priming effect of biochar are short-term incubations, and the extrapolation of results to predict long-term effects may be critical [22]. For all these reasons, there is the need to evaluate biochar stability and its effect on SOM in field experiments over a sufficient time, to evaluate the real efficacy of the biochar option to sequester soil $\mathrm{C}$ in the long term.

Co-application of compost and biochar can have several advantages in terms of plant nutrition, soil biological activity, and degradation of toxic substances that could be contained in biochar $[15,23,24]$. Composting is the biological decomposition and stabilization of organic matter derived from plants, animals, or humans through the action of diverse microorganisms under aerobic conditions. However, as compost has only a moderate $C$ sequestration potential, it is important to verify if the association with biochar could impact the soil C sequestration potential and/or priming effect.

This paper reports the results of a two-year field experiment carried out in a vineyard, in temperate climatic conditions, where biochar was applied alone or in combination with compost. This work aims to evaluate the impact of biochar on the climate change mitigation potential of agricultural soils, and more specifically to answer the following scientific questions:

1. How stable is woodchips biochar if it is applied to agricultural soils in temperate climatic conditions?

2. Can woodchips biochar increase the $C$ stock of agricultural soils in temperate climatic conditions?

3. Does compost application together with biochar affect the stability and $\mathrm{C}$ sequestration potential of biochar?

To answer these questions, biochar decay rate and the effect of biochar, alone or in association with compost, on the soil $C$ stock were estimated with two analytical methods: an isotopic mass balance approach and the assessment of Benzene PolyCarboxylic Acids (BPCAs), specific molecular markers for stable condensed aromatic $C$ structures $[25,26]$.

\section{Material and Methods}

\subsection{Experimental Site and Treatments Application}

The present work is the result of a field experiment carried out in a mature vineyard (cv. Müller Thurgau, planted in 2007 and grafted onto SO4) located near Merano (BZ, Northern Italy, $\left.46^{\circ} 40^{\prime} 2.374^{\prime \prime} \mathrm{N}, 11^{\circ} 11^{\prime} 43.476^{\prime \prime} \mathrm{E}\right)$, at an altitude of about $600 \mathrm{~m}$ a.s.l., managed by the 
Laimburg Research Center. The average annual temperature of the area, during the 2 years of experiment was $10.8^{\circ} \mathrm{C}$ and the average annual rainfall $896.9 \mathrm{~mm}$ (Fragsburg weather station, Merano).

The soil is sandy-loam, according to the USDA classification, with a content of $64 \%$ sand, $24 \%$ silt, and 7\% clay. It is a shallow, skeleton-rich, Dystric Eutrochrept (USDA, 1999). The soil organic $\mathrm{C}$ content is $24 \pm 8 \mathrm{~g} \mathrm{~kg}^{-1}$, the $\mathrm{pH}$ is $6.4 \pm 0.2$, the bulk density $1.1 \pm 0.1 \mathrm{~g} \mathrm{~cm}^{-3}$ and the isotopic signature $\left(\delta^{13} \mathrm{C}\right)-27.78 \pm 0.79 \%$. The field has a $10 \%$ slope. During the experimental period, no fertilization was applied, and vines were irrigated through drip irrigation only in the first year. More specifically, in 2017 vines were irrigated 8 times between April and July with, on average, $18.7 \mathrm{~L}$ of water/vine each time.

On 2 May 2017, biochar was applied to the soil at two rates: 25 and $50 \mathrm{t} \mathrm{ha}^{-1}$, alone or in combination with $45 \mathrm{tha}^{-1}$ of compost. A total of 6 treatments were compared: non-amended control soil (N); $25 \mathrm{tha}^{-1}$ of biochar (B1); $50 \mathrm{tha}^{-1}$ of biochar (B2); $45 \mathrm{tha}^{-1}$ of compost (C); $25 \mathrm{t} \mathrm{ha}^{-1}$ of biochar $+45 \mathrm{t} \mathrm{ha}^{-1}$ of compost (B1C); $50 \mathrm{t} \mathrm{ha}^{-1}$ of biochar $+45 \mathrm{tha}^{-1}$ of compost (B2C). Soil amendments were incorporated into the top $15 \mathrm{~cm}$ of soil through superficial soil tillage. The soil was also tilled in the control plots to guarantee comparable conditions in all treatments. Four replicates were prepared for each experimental treatment. The resulting 24 experimental plots were distributed according to a randomized blocks design. Each plot had an area of approximately $80 \mathrm{~m}^{2}$ and hosted 20 vine plants, distributed in two parallel rows. In each plot, soil amendments were distributed in the inter-row between the two plant rows, and half of the two adjacent inter-rows.

The biochar used in the experiment consisted of small fragments $(<5 \mathrm{~mm})$ and was produced from coniferous woodchips at a temperature of about $500{ }^{\circ} \mathrm{C}$ through fast pyrolysis by Record Immobiliare Srl (Lunano, PU, Itlay). A detailed description of the physicochemical characteristics of biochar is reported in Table 1 . Before application to the soil, biochar was moistened to reach a water content of $20 \%(w / w)$.

Table 1. Physicochemical characteristics of the biochar used in the present work.

\begin{tabular}{cccc}
\hline Property & Unit & Value & Uncertainty \\
\hline $\mathrm{pH}$ & - & 12.4 & \pm 0.5 \\
Bulk density & $\mathrm{g} \mathrm{cm}^{-3}$ & 0.165 & - \\
Sieve fraction $<5 \mathrm{~mm}$ & $\%$ & 100 & \pm 10 \\
Sieve fraction $<2 \mathrm{~mm}$ & $\%$ & 97 & \pm 10 \\
Sieve fraction $<0.5 \mathrm{~mm}$ & $\%$ & 70 & \pm 7 \\
Max. water retention & $\% w / w$ & 86 & \pm 7 \\
Ash $\left(550^{\circ} \mathrm{C}\right)$ & $\%$ & 31 & \pm 3 \\
Total C & $\%$ & 58.9 & - \\
$\mathrm{C}$ from CaCO & $\%$ & 1.1 & - \\
Organic $\mathrm{C}$ & $\%$ & 57 & \pm 5 \\
$\mathrm{H}: \mathrm{C}$ molar ratio & - & 0.10 & \pm 0.01 \\
Total N & $\%$ & 0.39 & \\
C:N & $\%$ & 151 & \\
Total P & $\%$ & 3.5 & \pm 0.04 \\
Total K & $\%$ & $<1$ & \\
PAHs 1 & $\mathrm{mg} / \mathrm{kg}$ & -24.81 & \pm 0.01 \\
$\delta^{13} \mathrm{C}$ & $\%$ & & \\
\hline
\end{tabular}

${ }^{1}$ Polycyclic aromatic hydrocarbon.

A detailed description of the physicochemical characteristics of compost used in the experiment is reported in Table 2. 
Table 2. Physicochemical characteristics of the compost used in the present work.

\begin{tabular}{ccc}
\hline Property & Unit & Value \\
\hline $\mathrm{pH}$ & - & 8.2 \\
Humidity & $\%$ & 21.1 \\
Bulk density & $\mathrm{g} \mathrm{cm}^{-3}$ & 0.936 \\
$\mathrm{NO}_{3}-\mathrm{N}^{*}$ & $\mathrm{mg} / \mathrm{L}$ & 94.4 \\
$\mathrm{NH}_{4}-\mathrm{N}^{*}$ & $\mathrm{mg} / \mathrm{L}$ & 203.1 \\
$\mathrm{Total} \mathrm{N}^{*}$ & $\mathrm{mg} / \mathrm{L}$ & 297.5 \\
$\mathrm{P}_{2} \mathrm{O}_{5}{ }^{*}$ & $\mathrm{mg} / \mathrm{L}$ & 139 \\
$\mathrm{~K}_{2} \mathrm{O}^{*}$ & $\mathrm{mg} / \mathrm{L}$ & 3764 \\
$\mathrm{Mg}^{*}$ & $\mathrm{mg} / \mathrm{L}$ & 394 \\
$\mathrm{Na}^{*}$ & $\mathrm{mg} / \mathrm{L}$ & 190 \\
Organic Matter & $\%$ & 16.5 \\
Total N & $\%$ & 0.72 \\
$\mathrm{C:N}$ & & 13 \\
$\delta^{13} \mathrm{C}$ & $\%$ & $-27.2 \pm 0.05$ \\
\hline
\end{tabular}

ॠCAT extraction method.

\subsection{Biochar Stability in Soil}

Biochar stability in soil was assessed with two distinct methods: an isotopic mass balance and the quantification of Benzene PolyCarboxylic Acids (BPCA).

\subsubsection{Isotopic Mass Balance}

In May 2017, two weeks before the distribution of soil amendments (time t0), two soil samples were collected from each experimental plot (48 samples in total), using a $48 \mathrm{~mm}$ diameter split tube sampler (Eijkelkamp, Giesbeek, Holland), up to a depth of $20 \mathrm{~cm}$. The samplings were repeated three weeks ( $\mathrm{t} 1), 1$ year ( $\mathrm{t} 2)$, and 2 years ( $\mathrm{t} 3$ ) after the application of the amendments to the soil. Samples were weighed and sieved at $2 \mathrm{~mm}$ to separate stones and roots from the fine earth. For a limited number of samples, the stones extracted were weighed and their volume was measured by water displacement, and the stone density was determined. The stone volume was calculated for all the other samples by dividing the stone weight -by the stone density. Soil organic C content (\%) and the isotopic signature $\left(\delta^{13} \mathrm{C}\right)$ were measured on dry sub-samples of fine earth $\left(24 \mathrm{~h}\right.$ at $\left.105^{\circ} \mathrm{C}\right)$ with a continuous flow isotopic ratio mass spectrometer (CF-IRMS; Delta V Advantage, Thermo Fisher Scientific, Bremen, Germany) coupled with a CHN elemental analyzer (Flash EA 2000 Thermo Fisher Scientific, Bremen, Germany). For each sample, soil bulk density ( $\rho$, $\mathrm{g} \mathrm{cm}^{-3}$ ) was determined by dividing the dry weight of the fine earth by the volume of sampled soil.

Because the difference between the isotopic signature of native soil organic matter (SOM) and biochar was higher than $2 \%$ and the variability was low [27], an isotopic mass balance was calculated, for each sampling time, using the following equation:

$$
f=\frac{\delta^{13} C_{\text {tot }}-\delta^{13} C_{S O M}}{\delta^{13} C_{\text {biochar }}-\delta^{13} C_{S O M}}
$$

where $f$ is the fraction of biochar-derived organic $C\left(C_{\text {biochar }} / C_{\text {tot }}\right), \delta^{13} C_{\text {tot }}, \delta^{13} C_{S O M}$ and $\delta^{13} C_{\text {biochar }}$ are the $C$ isotopic signatures of the amended soil, native soil organic matter and biochar, respectively. The value of $\delta^{13} C_{S O M}$ was measured for soil samples before the application of biochar $(\mathrm{t} 0,-27.78 \pm 0.79 \%)$. Since a single isotope, two end-member isotopic mass balance can only be applied when two sources of $C$ are present in the soil, this method was used only for treatments B1 and B2 and not for treatments B1C and B2C. In the latter in fact, the presence of compost represented a third $C$ source, which could have impaired the application of the method. The amount of biochar-derived C (biochar- 
C) contained in the first $20 \mathrm{~cm}$ of soil was therefore determined through the following equation:

$$
\text { Biochar-C }\left[\mathrm{t} \mathrm{ha}^{-1}\right]=f \times \mathrm{C}_{\mathrm{org}}[\%] / 100 \times \rho_{\mathrm{c}}\left[\mathrm{g} \mathrm{cm}^{-3}\right] \times 20[\mathrm{~cm}] \times 100
$$

where $C_{\text {org }}$ is the total soil organic $C$ content and $\rho_{\mathrm{c}}$ is the soil bulk density corrected for the presence of stones by subtracting the stone volume from the total volume of the sample.

The $\%$ of biochar-C remaining at each sampling time, as compared to the amount initially applied, was calculated by dividing the amount of biochar-C obtained from equation [2] by the amount of biochar-C initially applied to the soil. The remaining biochar amounts were then interpolated with an exponential decay model for both treatments:

$$
C_{t}=a e^{-k t}
$$

where $C_{t}$ is the percentage of biochar-C remaining in the soil at time $t, a$ is the modeled initial amount of biochar- $C$ in soil, and $k$ is the daily decomposition constant of biochar. According to this model, the Mean Residence Time of biochar in the soil (MRT, years) was calculated as $1 /(k \times 365)$.

\subsubsection{Assessment of BPCA}

The biochar-derived $C$ (biochar-C) was also quantified through the analysis of specific molecular markers for black carbon (Benzene PolyCarboxylic Acids, BPCAs), according to the method proposed by [26]. The analyses were done in the laboratories of the Martin Luther University of Halle-Wittenberg (Germany), on soil samples collected before the beginning of the experiment ( $\mathrm{t} 0), 3$ weeks after biochar distribution ( $\mathrm{t} 1)$, and 2 years later (t3). After quantifying the BPCA content of soil samples, the soil black $\mathrm{C}$ content was calculated by multiplying the BPCA content by (biochar BPCA concentration/biochar organic C).

Results were then expressed in tons per hectare (biochar-C, $\mathrm{tha}^{-1}$ ) using the following equation:

$$
\text { Biochar-C }=\mathrm{C}_{\mathrm{BPCA}}\left[\mathrm{g} \mathrm{kg}^{-1}\right] \times \rho\left[\mathrm{g} \mathrm{cm}^{-3}\right] \times 20[\mathrm{~cm}] \times 10
$$

where $\mathrm{C}_{\mathrm{BPCA}}$ is the soil black $\mathrm{C}$ content $\left(\mathrm{g} \mathrm{kg}^{-1}\right)$ quantified through the analysis of BPCAs.

To evaluate biochar stability in the soil, the amount of biochar-C estimated at each sampling time through BPCAs was corrected by subtracting the black $C$ content naturally present in the soil before the distribution of biochar ( $\mathrm{t} 0$ samples). Since BPCA analyses were made on samples collected from all treatments at only two sampling times ( 3 weeks after biochar distribution, $\mathrm{t} 1$ and 2 years later, $\mathrm{t} 3$ ), it was not possible to calculate biochar decomposition rate using an exponential model, as in the case of the isotopic mass balance.

\subsection{Priming Effect of Biochar on SOM}

The priming effect was determined based on the results of the isotopic mass balance for N, B1 and B2 treatments, and the results of BPCA analysis for all treatments. At each sampling time, the amount of $C$ in soil organic matter (SOM-C) was determined in the amended plots by subtracting the amount of biochar- $\mathrm{C}$ from the total soil organic $\mathrm{C}$ stock. The occurrence of the priming effect of biochar on SOM was assessed by comparing the amount of SOM-C in the control soil with the SOM-C content in the biochar-treated plots. The occurrence of the priming effect of biochar on SOM in the case of the presence of compost was instead assessed by comparing the amount of SOM-C in the compost-treated plots with the SOM-C content in the biochar + compost-treated plots.

\subsection{Statistical Analysis}

Results for all measured properties are presented as the average of 4 replicates for each treatment \pm standard error. To identify significant differences in soil $C$ stock, biochar$\mathrm{C}$ concentration, biochar-C stock, and SOM-C stock between treatments or sampling times, statistical comparisons were based on linear models using the nlme package in $\mathrm{R}$ 
software [28]. Multiple comparisons were performed with the Student-Newman-Keuls test (SNK).

No data autocorrelation structure was imposed in the model between the different sampling times, as the introduction of an autocorrelation structure did not result in a decrease of the Akaike Information Criterion (AIC). As a significant interaction was detected between time and treatment, the effect of biochar and compost on total $C$ at each sampling time was detected by linear models, using a factorial design with interaction.

Homogeneity of variances was checked before ANOVA by plotting standardized residuals against fitted values. When this condition was not fulfilled, the variance structure was selected by specifying the weights argument in the model [29].

Biochar- $\mathrm{C}$ values measured with the isotopic mass balance were interpolated with an exponential model through a non-linear regression analysis, using the STATA 16 software (StataCorp LLC, College Station, TX, USA).

A confidence level of $95 \%$ was used for all the analyses.

\section{Results}

\subsection{Biochar Stability in the Soil}

According to the isotopic mass balance three weeks after biochar application, in the B1 treatment we found, on average, $13 \pm 2 \mathrm{t} \mathrm{ha}^{-1}$ of biochar- $C$ corresponding to $80 \pm 9 \%$ of the applied biochar-C, while in the B2 treatment we found $31 \pm 6 \mathrm{t} \mathrm{ha}^{-1}$ corresponding to $95 \pm 18 \%$ of the applied amount (Figure 1). After about one year (385 days), the amount of biochar-C found in soil was $11 \pm 2 \mathrm{tha}^{-1}$ in treatment $\mathrm{B} 1$ and $29 \pm 5 \mathrm{tha}^{-1}$ in treatment $\mathrm{B} 2$, corresponding to $70 \pm 14 \%$ and $91 \pm 16 \%$ of the applied amount, respectively (Figure 1 ). Finally, after about two years (745 days), $6.5 \pm 2.7 \mathrm{tha}^{-1}$ and $22.3 \pm 10.0 \mathrm{tha}^{-1}$ of biochar were found in soil in treatments B1 and B2, respectively, corresponding to $40 \pm 17 \%$ and $69 \pm 31 \%$ of the distributed biochar-C, respectively (Figure 1).

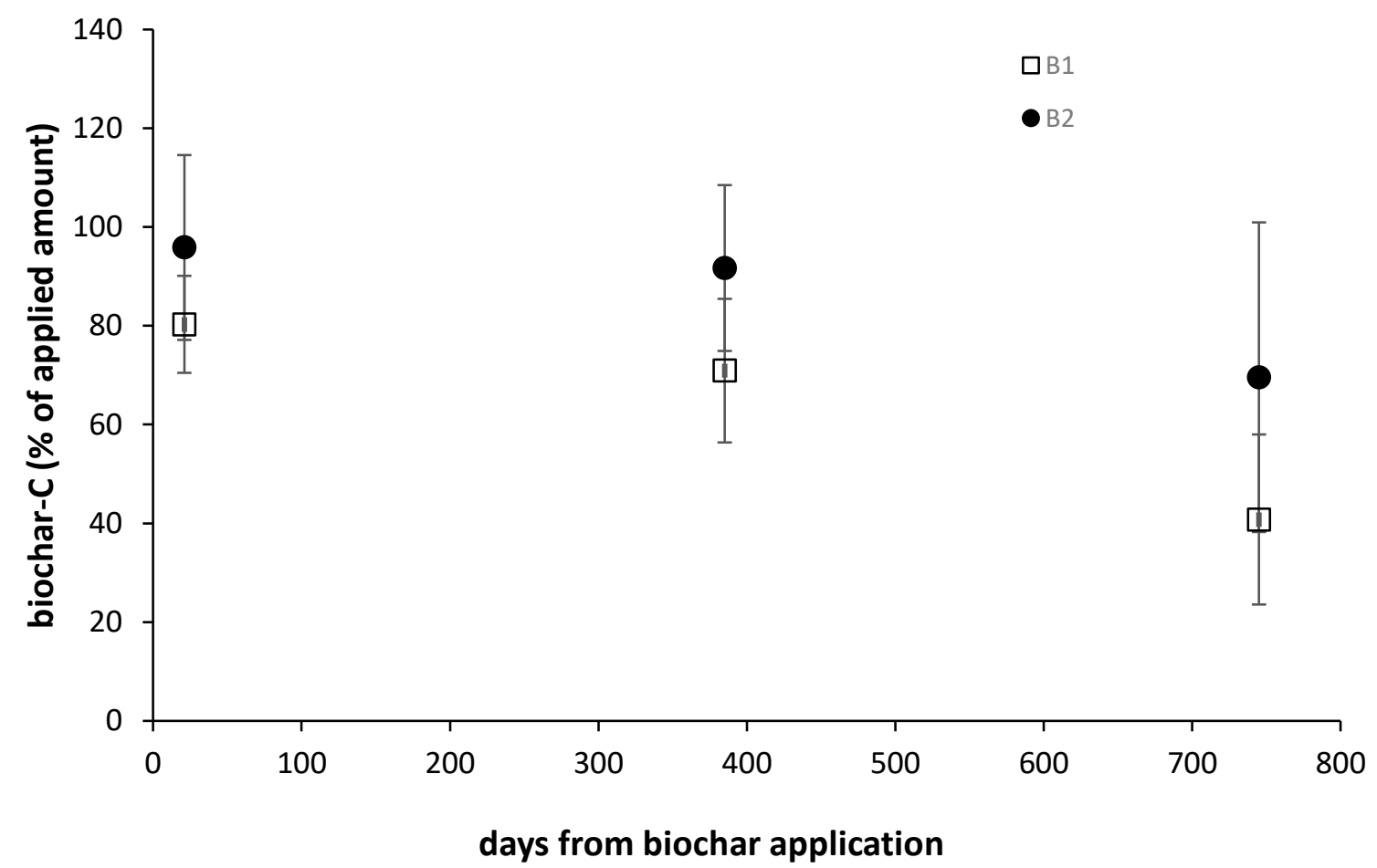

Figure 1. Biochar-C in soil (\% of the applied amount) at 21 (t1), $385(\mathrm{t} 2)$, and $745(\mathrm{t} 3)$ days after application of biochar in treatments B1 (25 tha ${ }^{-1}$ of biochar) and B2 (50 tha $\mathrm{t}^{-1}$ biochar). Values shown in the graph are the results of the isotopic mass balance approach. The vertical bars represent the standard error of the mean. 
In both B1 and B2 treatments the daily decay rate parameter $(k)$, estimated through the negative exponential model, was not statistically significant ( $p$-values were 0.087 and 0.214 for B1 and B2 treatments, respectively) (Figure 1, Table 3). For this reason, no biochar MRT was estimated and reported in this work.

Table 3. Exponential decay model parameters and model statistical significance.

\begin{tabular}{cccc}
\hline Soil Treatments & \multicolumn{2}{c}{ Model Parameters } & $p$-Value \\
\cline { 2 - 4 } & $\boldsymbol{a}$ & $\boldsymbol{k}$ & \\
\cline { 2 - 4 } B1 & 87.95 & 0.0004 & 0.087 \\
B2 & 100.56 & 0.0009 & 0.214 \\
\hline
\end{tabular}

According to the BPCA analysis, before the distribution of soil amendments, $7.5 \pm 0.1 \mathrm{~g} \mathrm{~kg}^{-1}$ of black $\mathrm{C}$ were already present in the soil (Figure 2). Three weeks after the distribution of soil amendments ( $\mathrm{t} 1$ ) in all treatments with biochar and biochar + compost a significant increase in biochar-C content was observed (Figure 2). In the same treatments, no significant variations were observed in the biochar- $\mathrm{C}$ content between sampling times $\mathrm{t} 1$ and $\mathrm{t} 3$ (two years after biochar application to soil) (Figure 2).

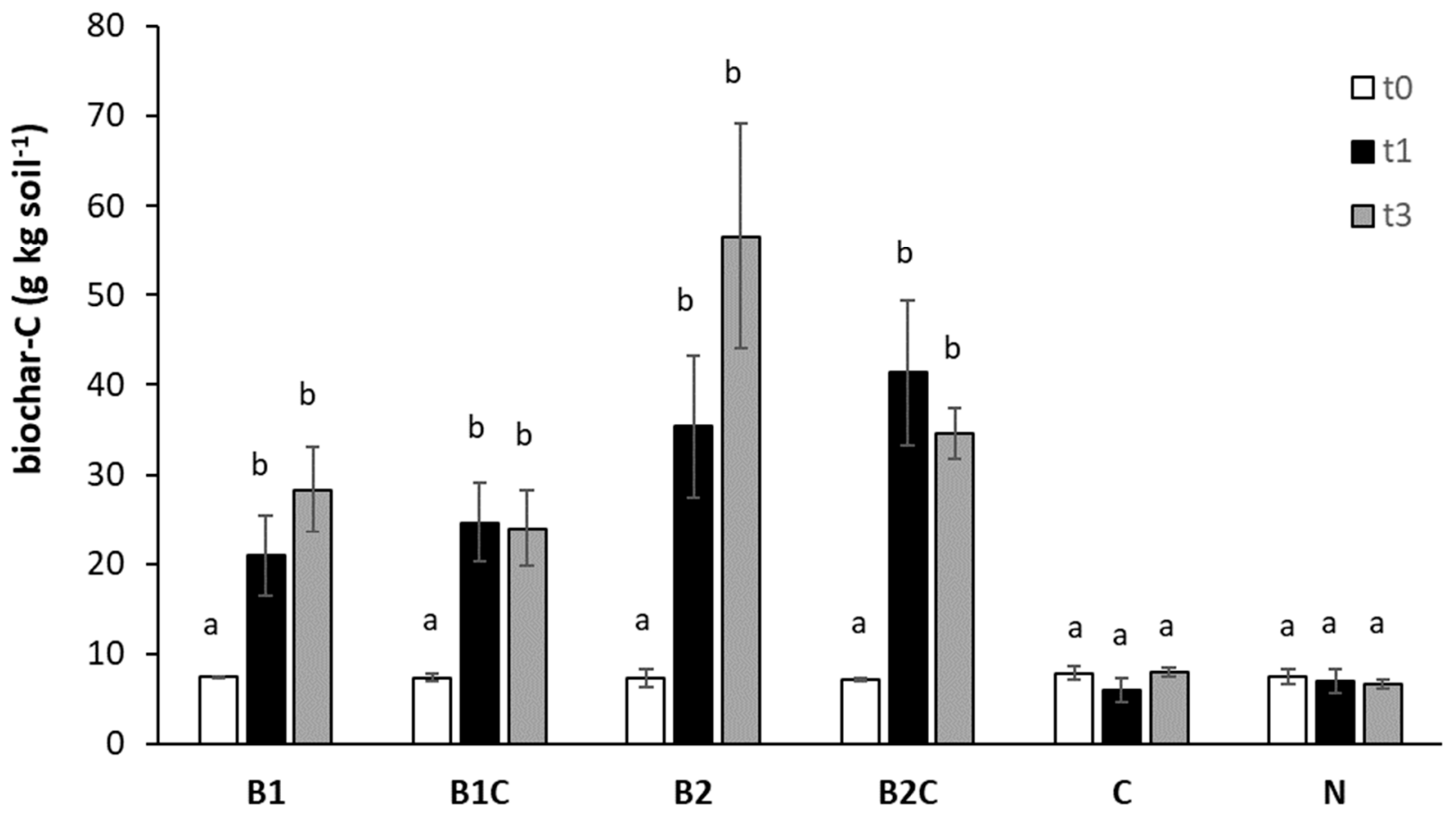

Figure 2. Biochar- $C$ content in the soil $\left(\mathrm{g} \mathrm{kg}^{-1}\right)$ according to BPCA analysis in the six experimental treatments: $\mathrm{N}$ (control), B1 (25 tha ${ }^{-1}$ biochar), B2 (50 $\mathrm{t} \mathrm{ha}^{-1}$ biochar), C (45 t ha ${ }^{-1}$ compost), B1C ( $25 \mathrm{t} \mathrm{ha}^{-1}$ biochar $+45 \mathrm{t} \mathrm{ha}^{-1}$ compost), B2C (50 tha ${ }^{-1}$ biochar $+45 \mathrm{t} \mathrm{ha}^{-1}$ compost) before the distribution of soil amendments (white bars, $\mathrm{t} 0$ ), 3 weeks later (black bars, $\mathrm{t} 1$ ) and 2 years later (gray bars, $\mathrm{t} 3$ ). Different letters above the bars indicate statistically significant differences between the sampling times within the same treatment $(p \leq 0.05)$. Vertical bars represent the standard error of the mean.

The amount of biochar- $\mathrm{C}$ found in the soil three weeks after biochar application (t1) was $8.4 \pm 3.8 \mathrm{t} \mathrm{ha}^{-1}$ in the B1 treatment, $12.5 \pm 3.7 \mathrm{t} \mathrm{ha}^{-1}$ in the B1C treatment, $20.5 \pm 5.7 \mathrm{t} \mathrm{ha}^{-1}$ in the B2 treatment and $24.2 \pm 6.2 \mathrm{t} \mathrm{ha}^{-1}$ in the B2C treatment (Figure 3). These quantities represent $52 \%$ and $78 \%$ of the amounts applied at the beginning of the experiment (15.9 t biochar-C ha ${ }^{-1}$ ) in treatments B1 and B1C, respectively, and $64 \%$ and $75 \%$ of the dose applied in treatments B2 and B2C (31.9 t biochar-C ha ${ }^{-1}$ ), respectively (Figure 3). Two years after biochar application ( $\mathrm{t} 3$ ), the BPCA method overestimated the biochar-C content of the soil for B1 and B2 treatments compared to the amount applied 
(Figure 3). At the same sampling time, in treatments B1C and B2C, $16.2 \pm 4.4 \mathrm{tha}^{-1}$ and $22.7 \pm 3.4 \mathrm{tha}^{-1}$ of biochar-C were estimated, respectively (Figure 3 ). The values of biochar-C estimated at the two sampling times did not differ significantly for any of the experimental treatments (Figure 3).

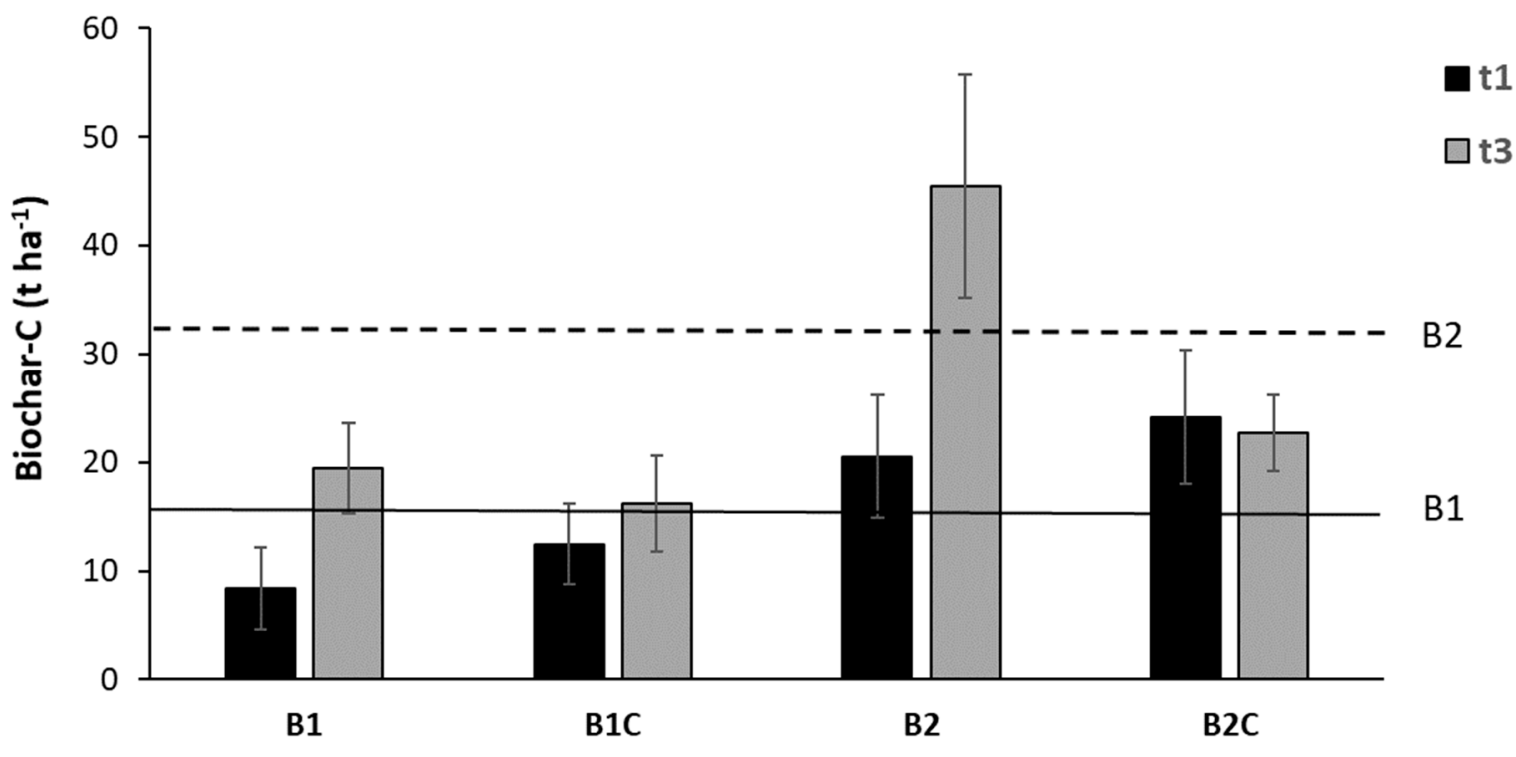

Figure 3. Biochar-C content in soil ( $\left.\mathrm{t} \mathrm{ha}^{-1}\right)$ according to BPCA analysis in the experimental treatments B1 ( $25 \mathrm{tha}{ }^{-1} \mathrm{biochar}$, B2 (50 t ha ${ }^{-1}$ biochar), B1C ( $25 \mathrm{t} \mathrm{ha}^{-1}$ biochar $+45 \mathrm{t} \mathrm{ha}^{-1}$ compost), and B2C (50 $\mathrm{t} \mathrm{ha}^{-1}$ biochar $+45 \mathrm{t} \mathrm{ha}^{-1}$ compost) 3 weeks after the application of soil amendments (black bars in the graph, $\mathrm{t} 1$ ) and 2 years later (gray bars, $\mathrm{t} 3$ ). The amount of biochar- $C$ naturally present in the soil before the distribution of amendments $(\mathrm{t} 0)$ was subtracted from the quantity measured in the soil samples at $\mathrm{t} 1$ and $\mathrm{t} 3$. The horizontal lines represent the doses of biochar-C applied (B1, continuous line and B2, dashed line). No significant differences were found between the time $\mathrm{t} 1$ and $\mathrm{t} 3(p \leq 0.05)$. Vertical bars represent the standard error of the mean.

Three weeks after biochar application to the soil (t1), the estimates of biochar-C obtained with the two analytical methods did not differ significantly (Figure 4). At this sampling time, the estimates obtained with the isotopic mass balance $\left(13 \pm 2 \mathrm{tha}^{-1}\right.$ and $31 \pm 6 \mathrm{t} \mathrm{ha}^{-1}$ of biochar-C for B1 and B2, respectively) were closer to the actual amount of biochar-C distributed ( $16 \mathrm{t} \mathrm{ha}^{-1}$ and $32 \mathrm{t} \mathrm{ha}^{-1}$ in $\mathrm{B} 1$ and $\mathrm{B} 2$ treatments, respectively), while the BPCA method provided lower estimates $\left(8 \pm 4 \mathrm{tha}^{-1}\right.$ and $21 \pm 6 \mathrm{t} \mathrm{ha}^{-1}$ of biochar-C in $\mathrm{B} 1$ and B2, respectively). Two years after biochar application (t3), the estimate of biochar-C obtained with the BPCA method, in the B1 treatment, was significantly higher $(+63.3 \%)$ than the estimate obtained with the isotopic mass balance, while in the B2 treatment no significant difference between the two methods was observed (Figure 4). 


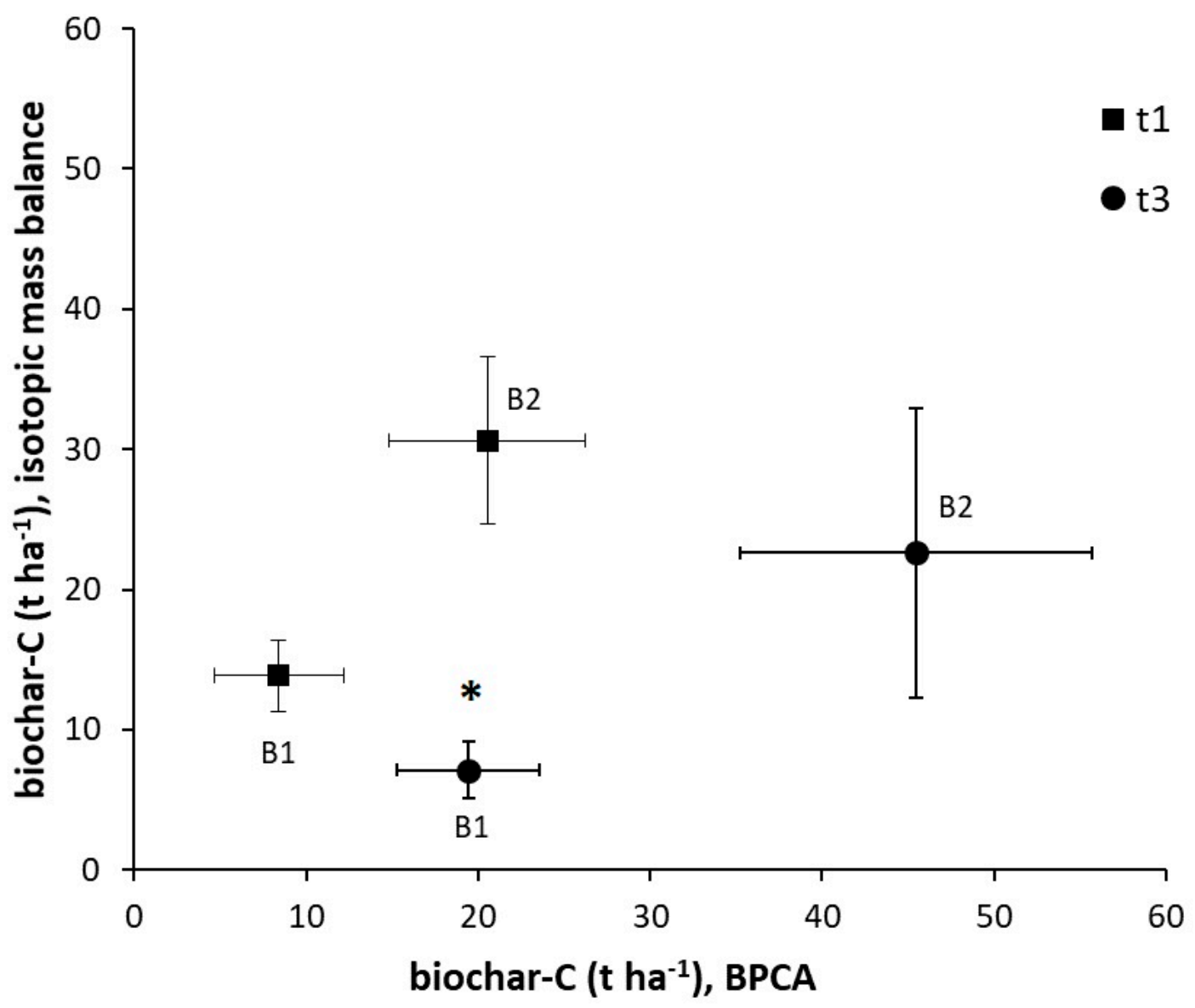

Figure 4. Comparison of soil biochar-C estimates $\left(\mathrm{t} \mathrm{ha}^{-1}\right)$ obtained using the isotopic mass balance method ( $\mathrm{Y}$-axis) and the BPCA analysis (X-axis) in treatments B1 and B2, three weeks after biochar application to soil (t1) and two years later ( $\mathrm{t} 3)$. The error bars represent the standard error of the mean and the asterisk indicates a significant difference between the estimates obtained with the two analytical methods.

\subsection{Effect of Biochar on Soil C Stock}

Three weeks after the application of soil amendments (t1), the total soil organic C stock in biochar treatments, either alone or in association with compost, was higher than in the control, with an average increase of $144 \pm 22 \%$ (Figure 5). However, no significant differences were found between the two application amounts. The application of compost alone did not result in any significant increase in soil C stock in comparison to the control, and no interaction effect was observed between biochar and compost treatments (Figure 5). Similar results were found after one year (t2) and two years (t3) (Figure 5), when the average $C$ stock increases consequent to biochar application were $66 \pm 10 \%$ and $72 \pm 13 \%$, respectively (Figure 5).

\subsection{Priming Effect of Biochar on SOM}

According to the results of both analytical methods (isotopic mass balance and analysis of BPCA), no significant differences were observed two years after biochar application (t3) between the SOM-C content in the biochar-treated soils compared to the control soils and in the biochar + compost treatments compared to the compost-treated soils (Figures 6 and 7). Therefore, we can conclude that no significant priming effect of biochar on the degradation of SOM was observed. 


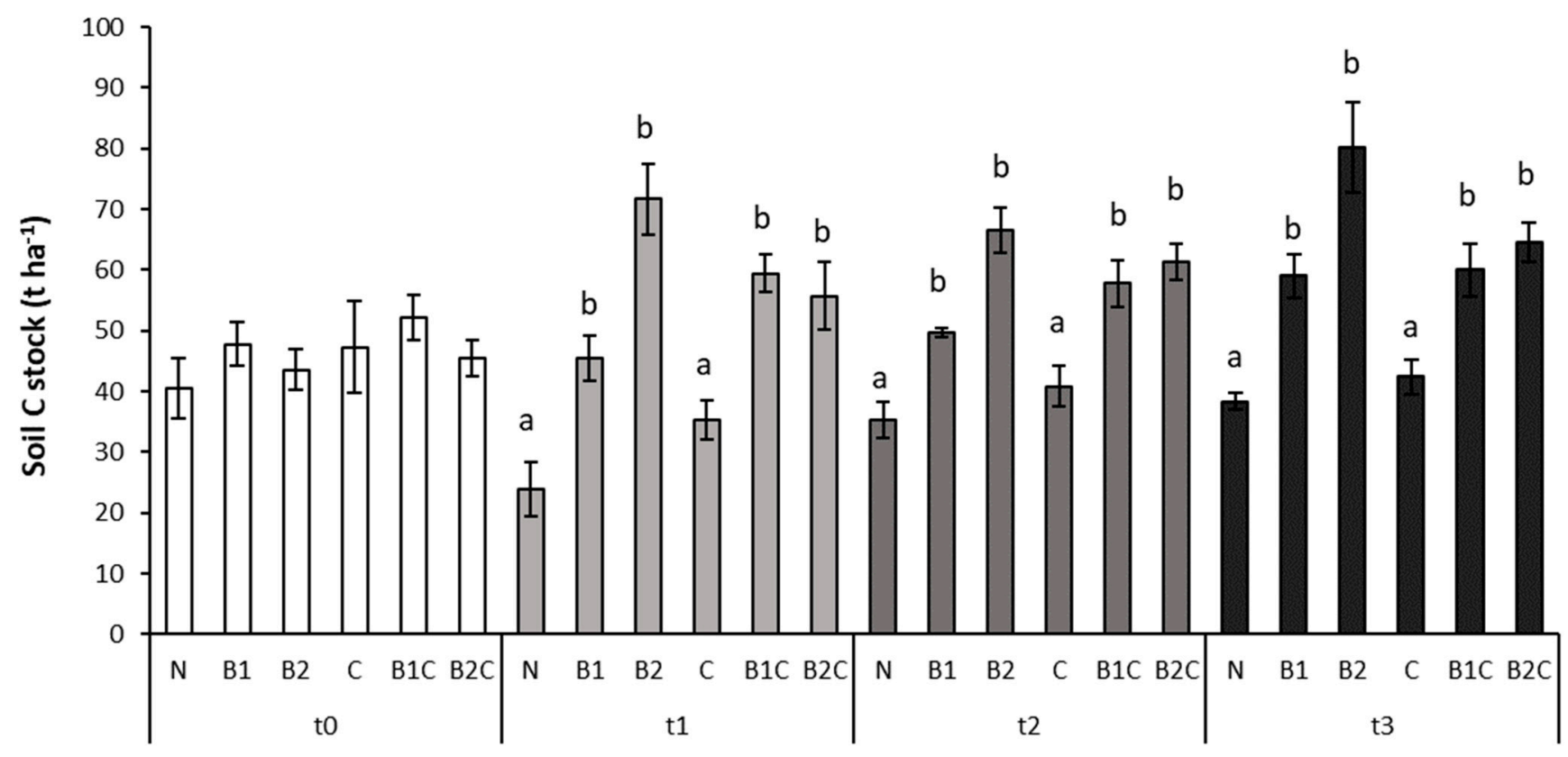

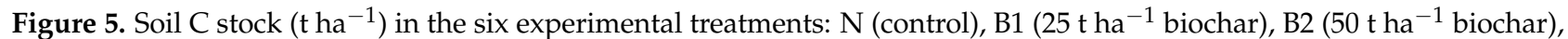
C ( $45 \mathrm{t} \mathrm{ha}^{-1}$ compost), B1C ( $25 \mathrm{t} \mathrm{ha}^{-1}$ biochar $+45 \mathrm{t} \mathrm{ha}^{-1}$ compost), and B2C (50 tha ${ }^{-1}$ biochar $+45 \mathrm{tha}{ }^{-1}$ compost) before the application of soil amendments ( $\mathrm{t} 0$, white bars), 3 weeks later ( $\mathrm{t} 1$, light gray bars), 1 year later ( $\mathrm{t} 2$, dark gray bars) and 2 years later ( $\mathrm{t} 3$, black bars). Letters above the bars indicate, if different, a statistically significant difference among the six soil treatments within the same sampling time $(p \leq 0.05)$. Vertical bars represent the standard error of the mean.

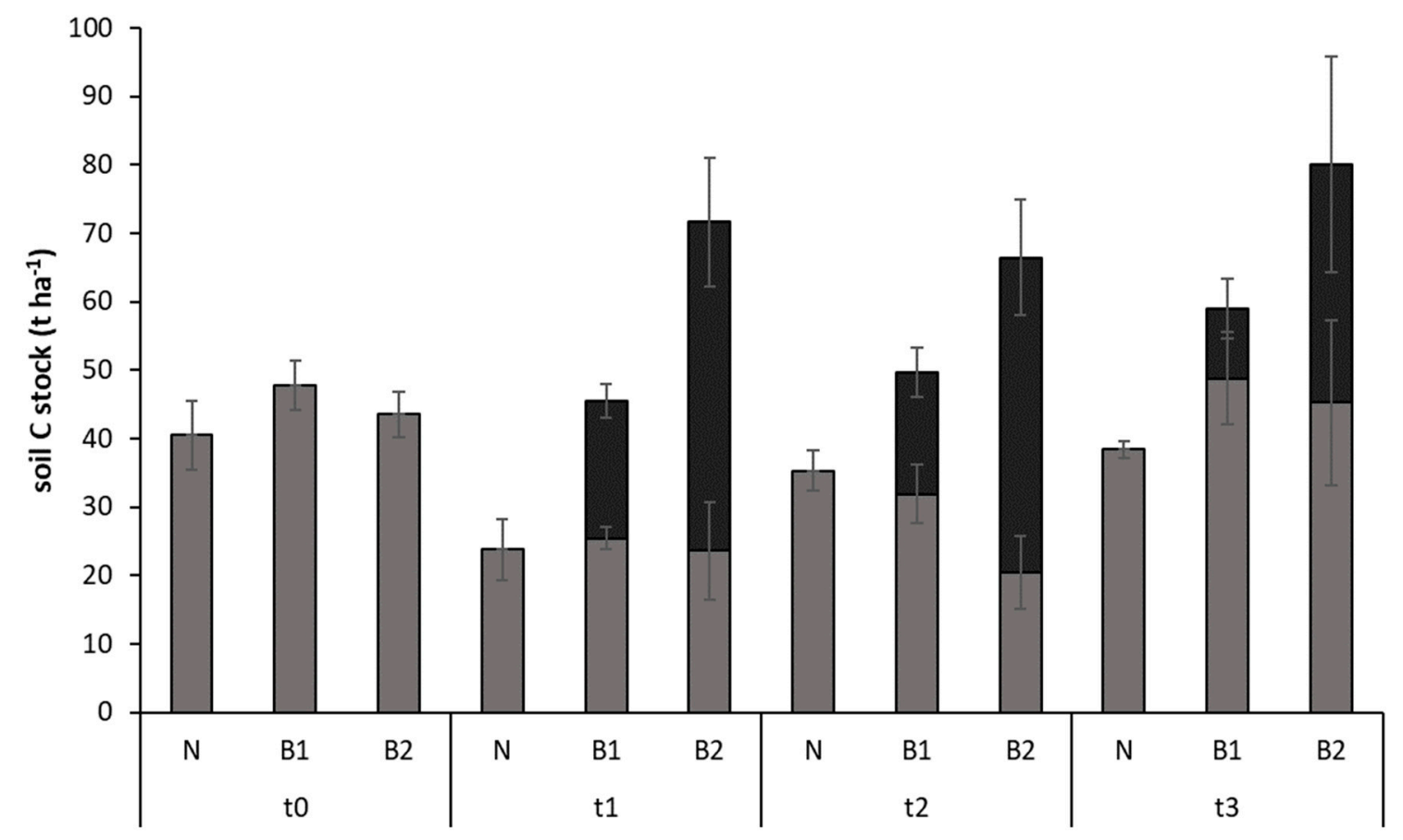

Figure 6. Soil $\mathrm{C}$ stock ( $\mathrm{t} \mathrm{ha}^{-1}$ ) divided into biochar-C (black bars) and SOM-C (gray bars) as assessed with the isotopic

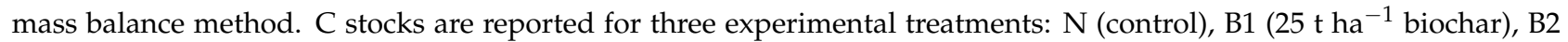
(50 tha ${ }^{-1}$ biochar) before the application of soil amendments ( $\left.\mathrm{t} 0\right), 3$ weeks later ( $\mathrm{t} 1$ ), 1 year later ( $\mathrm{t} 2$ ) and 2 years later ( $\mathrm{t} 3$ ). No statistically significant differences were observed $(p \leq 0.05)$. Vertical bars represent the standard error of the mean. 


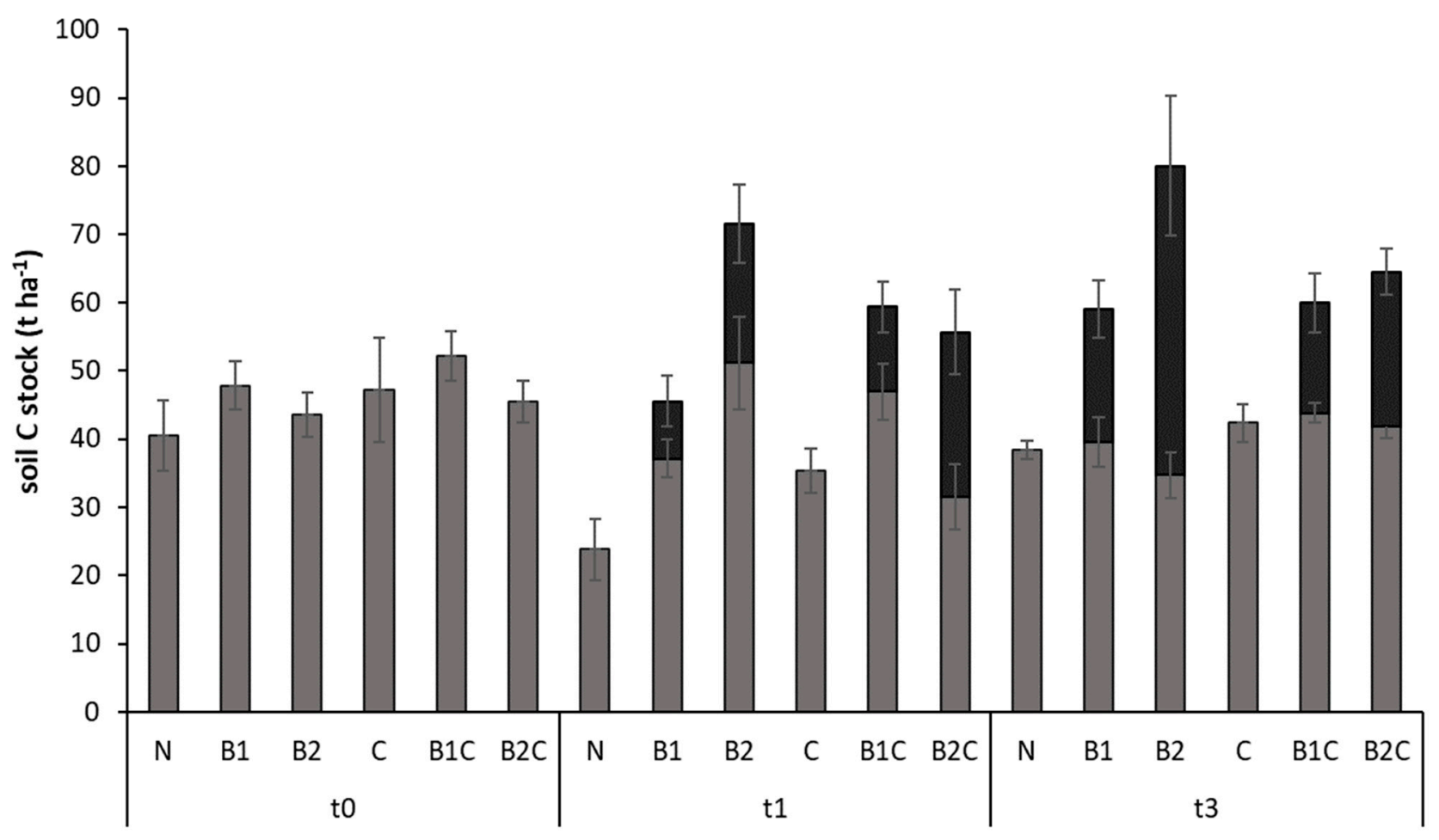

Figure 7. Soil $\mathrm{C}$ stock $\left(\mathrm{t} \mathrm{ha}^{-1}\right)$ divided into biochar-C (black bars) and SOM-C (gray bars) as assessed with the BPCA method. C stocks are reported for six experimental treatments: $\mathrm{N}$ (control), B1 ( $25 \mathrm{t} \mathrm{ha}^{-1}$ biochar), B2 (50 $\left.\mathrm{tha}^{-1} \mathrm{biochar}\right) \mathrm{C}$

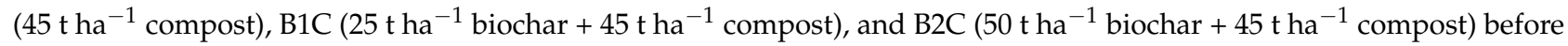
the application of soil amendments ( $\mathrm{t} 0), 3$ weeks later ( $\mathrm{t} 1$ ), and 2 years later ( $\mathrm{t} 3$ ). No statistically significant differences were observed. Vertical bars represent the standard error of the mean.

\section{Discussion}

The estimation of biochar amounts remaining in the soil over time obtained with the isotopic mass balance and the analysis of BPCAs, did not show any significant degradation of biochar in soil for both applied amounts. These results highlighted a substantial biochar stability over the two years of experiment duration and were in line with most of the literature reporting a long biochar MRT in the soil. Wang et al. (2016) [11], in a metaanalysis, which summarizes the results of 24 scientific articles, authors reported an average MRT of $556 \pm 483$ years, for the most stable fraction of biochar, which, according to the authors, represented $97 \%$ of the total biochar-C. However, the results of [11] were associated with high uncertainty. Also in the meta-analysis of Singh et al. (2012) [30], the authors report a high variability in the biochar MRT, with values ranging from 1 to 750 years. This high variability can be explained by the variability of biochar chemical and physical characteristics, as well as the difference in experimental conditions and duration [11]. In particular, laboratory incubations, which represent so far the majority of the studies on biochar stability in the literature, may not adequately represent open field conditions because they exclude meteorological events, exposure to ozone and UV rays, freeze-thaw cycles, and the presence of roots, factors that may accelerate the physical degradation and chemical oxidation of biochar [10,31-33]. For example, in Ventura et al. (2018) [14], the authors observed a fast decomposition rate for biochar in the field (MRT: 24.3 years for the more recalcitrant part of biochar, in cases of the absence of roots). Instead, on average, field mid-term studies showed a slower, even if not significantly, decomposition rate compared to incubation studies. The general short-term duration of laboratory experiments leads to estimating a biochar decay rate based on the decomposition observed mainly on the labile $C$ pool of biochar, therefore causing an underestimation of biochar stability in soil [11].

The stability of biochar is not only influenced by the experimental method, but also by the feedstock used for biochar production [11]. For instance, the biochar used in Ventura 
et al. (2018) [14] was produced with maize silage, while biochar produced from woody material is generally more stable than crop- or grass-derived biochar [11]. This could explain why the biochar used in the present study, which was produced from wood chips, did not show any significant decomposition in the experimental period, even if it was distributed in the field.

In our experiment, after three weeks from the application of $25 \mathrm{t} \mathrm{ha}^{-1}$ of biochar (B1 treatment), around $20 \%$ of the biochar was lost. This result may have been affected by operational inaccuracies (i.e., possible heterogeneous distribution of biochar in the field) but another hypothesis is that biochar losses occurred during biochar unloading and distribution operations because the biochar used in the experiment was made of very fine particles and characterized by a very low density. Biochar may have been carried by the wind outside the experimental field, as it was shown that the wind can cause losses of up to $28 \%$ of the applied biochar [34]. To limit these losses, biochar was moistened to reach a water content of $20 \%(w / w)$ before its application to the soil and was incorporated in the soil immediately after its distribution. However, we cannot exclude that some losses by wind transport occurred. Part of the biochar may also have been transported away by water runoff, given the slope of the site $(10 \%)$, or to the deeper soil layers by percolation because of the coarse soil texture and the high content of stones. It was shown that runoff may transport more than $50 \%$ of the distributed biochar outside the experimental field $[34,35]$ and percolation between $1.2 \%$ and $15.7 \%$ within one year from application [36].

For all of these reasons, field investigations appear to be fundamental, and the present study is one of the few works performed in field conditions with more than two years of observations.

Another important factor affecting biochar stability in the soil is the production process. We can hypothesize that if the biochar used in the present experiment was produced at a higher temperature $\left(>500{ }^{\circ} \mathrm{C}\right)$, the overall stability shown in this article would have been confirmed. Temperatures higher than $500{ }^{\circ} \mathrm{C}$ generally lead to longer half-lives by promoting more stable $\mathrm{C}$ structures in the biochar, causing a reduction of biochar-C bioavailability and lower $\mathrm{O} / \mathrm{C}$ ratios [37]. More specifically, it was shown that fast pyrolysis at low temperatures may result in the incomplete conversion of cellulosic and hemicellulosic fractions of biomass owing to the short residence time of the biomass in the pyrolysis reactor [38].

The assessment of biochar amount in the soil with BPCAs analysis showed that biochar stability is confirmed also when it is applied in combination with compost. Similar results were found in other field experiments with similar duration [26,39]. Analysis of BPCAs also showed an apparent increase, although not significant, in biochar- $C$ content in the soil between sampling time $\mathrm{t} 1$ (three weeks after biochar application) and $\mathrm{t} 3$ (two years later) (Figure 3), especially in treatments B1 and B2. A similar increase has been observed in previous studies [26,40]. For example, Glaser and Knorr (2008) [40] observed a 25\% increase in soil black $\mathrm{C}$ contentthat was not attributable to biochar amendment. The increase in BPCA concentration in the soil has been associated with multiple factors. On the one hand, the analytical results may have been affected by analytical inaccuracies, given the complexity of the laboratory protocols [41]. On the other hand, black pigments can be produced in-situ by various species of fungi, such as Aspergillus niger and Cercosporina Kikuchii (Matsumoto-et-Tomoyasu) [40,41].

It should be noticed that the estimates of biochar stability in the soil obtained in this study with both analytical methods are characterized by high uncertainty, because of the high natural heterogeneity and spatial variability observed in soil. On the other hand, as already mentioned above, there is a need for field trials to assess the absolute biochar stability in soil, and the present study is one of the few works performed in field conditions with more than two years of observations.

It is also important to highlight that the total $\mathrm{C}$ content in the soil significantly increased in the treatments with biochar (Figure 5) and the increase in soil C stock was detected also when biochar was associated with compost, indicating that the application 
of compost does not affect the potential of biochar to store $C$ in the soil in the medium term (Figure 5). Similar results were reported in previous studies in an Oxisol soil of the Colombian savannah [42], where the total $C$ content of the soil doubled after the application of $23.3 \mathrm{t} \mathrm{ha}^{-1}$ of biochar, and by Busch and Glaser (2015) [26], who reported a 1.7-factor increase in soil C content after one year from the application of $25 \mathrm{tha}^{-1}$ of co-composted biochar, as well as by Liu et al. (2012) [43], who observed an increase in total C in the soil by a factor of 2.5 after the application of $20 \mathrm{tha}^{-1}$ of biochar and $32.5 \mathrm{t} \mathrm{ha}^{-1}$ of compost.

The present study did not show the occurrence of any positive priming effect of biochar on soil organic matter, indicating that woodchips biochar can be applied in similar soil and climatic conditions without concerns about the stability of the native soil organic matter. The absence of a significant priming effect induced by biochar has been shown in previous studies [44,45] and also in the meta-analysis by Wang et al. (2016) [11]. However, many other studies have shown that biochar can induce either a positive or negative priming effect, i.e., stimulate or reduce the decomposition of soil organic matter $[14,19,22,46,47]$. It is interesting to notice that, in the literature, positive priming has usually been observed in the first experimental period, while negative priming has been observed in the longer term. More specifically, in a mata-analysis Maestrini et al. (2015) [22] calculated the cumulated effect of these two conditions over time, highlighting that the initial positive priming is counterbalanced by negative priming occurring at a time of approximately 600 days, which is close to the experimental length of the present study (745 days). However, we did not observe a priming effect at any of the sampling times. On the other hand, considering the soil texture in the experimental site, we could have expected a higher stimulation of SOM degradation, as highlighted for sandy soils in the meta-analysis of Wang et al. (2016) [11]. However, also in this case it should be considered that most of the studies on the biochar priming effect were short-term laboratory incubations [22], while there is a lack of data from longer experiments and field research.

\section{Conclusions}

The experimental results of the present field study indicated that woodchips biochar is stable in the soil, over a time of two years if applied alone or in combination with compost. However, considering that the estimate of the biochar amount in the soil showed a high uncertainty, it is not possible to draw firm conclusions on this aspect. However, the study showed that the application of biochar led to a significant increase in the total soil C stock and did not affect the stability of the native soil organic matter. These results were also confirmed when biochar was applied together with compost, showing the compatibility of these two amendments in terms of soil $\mathrm{C}$ sequestration. For these reasons, we can conclude that the application of biochar in the soils of alpine regions may be a strategy for the agricultural sector to increase $C$ storage in soil, contributing to climate change mitigation in the medium term.

Author Contributions: Conceptualization, G.T., M.V.; Methodology, G.T., M.V., B.G., K.W., C.C.; Validation, M.V., G.T., I.C., B.R., B.G. and K.W.; Formal analysis, I.C., C.C. and M.V.; Investigation, M.V., I.C., P.P., B.R., M.L. and K.W.; Resources, I.C., M.V., P.P., K.W., and B.G.; Data Curation, I.C., M.V.; Writing—original draft preparation, I.C. and M.V.; Writing—review and editing, I.C., M.V., P.P., G.T., K.W., B.R. and B.G.; Visualization, I.C. and M.V.; Supervision, G.T.; Project administration, G.T.; Funding acquisition, G.T. All authors have read and agreed to the published version of the manuscript.

Funding: This research was funded by the Wood-Up project (Optimization of WOOD gasification chain in South Tyrol to produce bioenergy and other high-value green products to enhance soil fertility and mitigate climate change, EFRE-FESR 2014-2020, project number 1028), funded by the European Regional Development Fund of the European Union and the Autonomous Province of Bolzano/Bozen.

Institutional Review Board Statement: Not applicable.

Informed Consent Statement: Not applicable. 


\section{Data Availability Statement: Not applicable.}

Acknowledgments: The authors would like to thank Martin Thalheimer of the Laimburg Research Center for providing information about the meteorological and soil characteristics of the experimental site. We also would like to thank Georg Trenkwalder and the staff who provided technical assistance for the set-up and management of the experimental site.

Conflicts of Interest: The authors declare no conflict of interest.

\section{References}

1. Liu, X.; Zhang, A.; Ji, C.; Joseph, S.; Bian, R.; Li, L.; Pan, G.; Paz-Ferreiro, J. Biochar's effect on crop productivity and the dependence on experimental conditions-A meta-analysis of literature data. Plant Soil 2013, 373, 583-594. [CrossRef]

2. Glaser, B.; Lehmann, J.; Zech, W. Ameliorating physical and chemical properties of highly weathered soils in the tropics with charcoal-A review. Biol. Fertil. Soils 2002, 35, 219-230. [CrossRef]

3. Glaser, B.; Birk, J.J. State of the scientific knowledge on properties and genesis of Anthropogenic Dark Earths in Central Amazonia (terra preta de Índio). Geochim. Cosmochim. Acta 2012, 82, 39-51. [CrossRef]

4. Ding, Y.; Liu, Y.; Liu, S.; Li, Z.; Tan, X.; Huang, X.; Zeng, G.; Zhou, L.; Zheng, B. Biochar to improve soil fertility. A review. Agron. Sustain. Dev. 2016, 36, 1-18. [CrossRef]

5. Blanco-Canqui, H. Biochar and Soil Physical Properties. Soil Sci. Soc. Am. J. 2017, 81, 687-711. [CrossRef]

6. Ventura, M.; Alberti, G.; Viger, M.; Jenkins, J.R.; Girardin, C.; Baronti, S.; Zaldei, A.; Taylor, G.; Rumpel, C.; Miglietta, F.; et al. Biochar mineralization and priming effect on SOM decomposition in two European short rotation coppices. GCB Bioenergy 2014, 7, 1150-1160. [CrossRef]

7. Hardy, B.; Sleutel, S.; Dufey, J.E.; Cornelis, J.-T. The Long-Term Effect of Biochar on Soil Microbial Abundance, Activity and Community Structure Is Overwritten by Land Management. Front. Environ. Sci. 2019, 7. [CrossRef]

8. Vaccari, F.; Baronti, S.; Lugato, E.; Genesio, L.; Castaldi, S.; Fornasier, F.; Miglietta, F. Biochar as a strategy to sequester carbon and increase yield in durum wheat. Eur. J. Agron. 2011, 34, 231-238. [CrossRef]

9. Criscuoli, I.; Alberti, G.; Baronti, S.; Favilli, F.; Martinez, C.; Calzolari, C.; Pusceddu, E.; Rumpel, C.; Viola, R.; Miglietta, F. Carbon Sequestration and Fertility after Centennial Time Scale Incorporation of Charcoal into Soil. PLoS ONE 2014, 9, e91114. [CrossRef]

10. Kuzyakov, Y.; Bogomolova, I.; Glaser, B. Biochar stability in soil: Decomposition during eight years and transformation as assessed by compound-specific 14C analysis. Soil Biol. Biochem. 2014, 70, 229-236. [CrossRef]

11. Wang, J.; Xiong, Z.; Kuzyakov, Y. Biochar stability in soil: Meta-analysis of decomposition and priming effects. GCB Bioenergy 2015, 8, 512-523. [CrossRef]

12. Gurwick, N.P.; Moore, L.A.; Kelly, C.; Elias, P. A Systematic Review of Biochar Research, with a Focus on Its Stability in situ and Its Promise as a Climate Mitigation Strategy. PLoS ONE 2013, 8, e75932. [CrossRef]

13. Lehmann, J.; Abiven, S.; Kleber, M.; Pan, G.; Singh, B.P.; Sohi, S.P.; Zimmerman, A.R. Persistence of biochar in soil. In Biochar for Environmental Management: Science, Technology and Implementation, 2nd ed.; Lehmann, J., Joseph, S., Eds.; Routledge: New York, NY, USA, 2015; pp. 235-282.

14. Ventura, M.; Alberti, G.; Panzacchi, P.; Vedove, G.D.; Miglietta, F.; Tonon, G. Biochar mineralization and priming effect in a poplar short rotation coppice from a 3-year field experiment. Biol. Fertil. Soils 2018, 55, 67-78. [CrossRef]

15. Schmidt, H.-P.; Kammann, C.; Niggli, C.; Evangelou, M.W.; Mackie, K.A.; Abiven, S. Biochar and biochar-compost as soil amendments to a vineyard soil: Influences on plant growth, nutrient uptake, plant health and grape quality. Agric. Ecosyst. Environ. 2014, 191, 117-123. [CrossRef]

16. Genesio, L.; Miglietta, F.; Baronti, S.; Vaccari, F.P. Biochar increases vineyard productivity without affecting grape quality: Results from a four years field experiment in Tuscany. Agric. Ecosyst. Environ. 2015, 201, 20-25. [CrossRef]

17. Baronti, S.; Vaccari, F.; Miglietta, F.; Calzolari, C.; Lugato, E.; Orlandini, S.; Pini, R.; Zulian, C.; Genesio, L. Impact of biochar application on plant water relations in Vitis vinifera (L.). Eur. J. Agron. 2013, 53, 38-44. [CrossRef]

18. Tammeorg, P.; Bastos, A.C.; Jeffery, S.; Rees, F.; Kern, J.; Graber, E.R.; Ventura, M.; Kibblewhite, M.; Amaro, A.; Budai, A.; et al. Biochars in soils: Towards the required level of scientific understanding. J. Environ. Eng. Landsc. Manag. 2016, 25, 192-207. [CrossRef]

19. Zimmerman, A.; Gao, B.; Ahn, M.-Y. Positive and negative carbon mineralization priming effects among a variety of biocharamended soils. Soil Biol. Biochem. 2011, 43, 1169-1179. [CrossRef]

20. Cross, A.; Sohi, S. The priming potential of biochar products in relation to labile carbon contents and soil organic matter status. Soil Biol. Biochem. 2011, 43, 2127-2134. [CrossRef]

21. Naisse, C.; Girardin, C.; Davasse, B.; Chabbi, A.; Rumpel, C. Effect of biochar addition on C mineralisation and soil organic matter priming in two subsoil horizons. J. Soils Sediments 2014, 15, 825-832. [CrossRef]

22. Maestrini, B.; Nannipieri, P.; Abiven, S. A meta-analysis on pyrogenic organic matter induced priming effect. GCB Bioenergy 2014, 7, 577-590. [CrossRef]

23. Fischer, D.; Glaser, D.F.A.B. Synergisms between Compost and Biochar for Sustainable Soil Amelioration. In Management of Organic Waste; InTech: London, UK, 2012; pp. 167-198. [CrossRef] 
24. Glaser, B.; Wiedner, K.; Seelig, S.; Schmidt, H.-P.; Gerber, H. Biochar organic fertilizers from natural resources as substitute for mineral fertilizers. Agron. Sustain. Dev. 2014, 35, 667-678. [CrossRef]

25. Glaser, B.; Haumaier, L.; Guggenberger, G.; Zech, W. Black carbon in soils: The use of benzenecarboxylic acids as specific markers. Org. Geochem. 1998, 29, 811-819. [CrossRef]

26. Busch, D.; Glaser, B. Stability of co-composted hydrochar and biochar under field conditions in a temperate soil. Soil Use Manag. 2015, 31, 251-258. [CrossRef]

27. Phillips, D.L.; Gregg, J.W. Uncertainty in source partitioning using stable isotopes. Oecologia 2001, 127, 171-179. [CrossRef] [PubMed]

28. Pinheiro, J.; Bates, D.; DebRoy, S.; Sarkar, D.; R Core Team. nlme: Linear and Nonlinear Mixed Effects Models; R Package Version 3.1-153; 2021. Available online: https:/ /CRAN.R-project.org/package=nlme (accessed on 27 September 2021).

29. Zuur, A.; Ieno, E.N.; Walker, N.; Saveliev, A.A.; Smith, G.M. Mixed Effects Models and Extensions in Ecology with R; Springer: New York, NY, USA, 2009.

30. Singh, N.; Abiven, S.; Torn, M.S.; Schmidt, M.W.I. Fire-derived organic carbon turnover in soils on a centennial scale. Biogeosciences Discuss. 2011, 8, 12179-12195. [CrossRef]

31. Spokas, K. Review of the stability of biochar in soils: Predictability of O:C molar ratios. Carbon Manag. 2010, 1, 289-303. [CrossRef]

32. Luo, Y.; Durenkamp, M.; De Nobili, M.; Lin, Q.; Brookes, P. Short term soil priming effects and the mineralisation of biochar following its incorporation to soils of different pH. Soil Biol. Biochem. 2011, 43, 2304-2314. [CrossRef]

33. Keith, A.; Singh, B.; Singh, B.P. Interactive Priming of Biochar and Labile Organic Matter Mineralization in a Smectite-Rich Soil. Environ. Sci. Technol. 2011, 45, 9611-9618. [CrossRef]

34. Major, J.; Lehmann, J.; Rondon, M.; Goodale, C. Fate of soil-applied black carbon: Downward migration, leaching and soil respiration. Glob. Chang. Biol. 2010, 16, 1366-1379. [CrossRef]

35. Rumpel, C.; Chaplot, V.; Planchon, O.; Bernadou, J.; Valentin, C.; Mariotti, A. Preferential erosion of black carbon on steep slopes with slash and burn agriculture. CATENA 2006, 65, 30-40. [CrossRef]

36. Singh, B.P.; Fang, Y.; Boersma, M.; Collins, D.; Van Zwieten, L.; Macdonald, L.M. In Situ Persistence and Migration of Biochar Carbon and Its Impact on Native Carbon Emission in Contrasting Soils under Managed Temperate Pastures. PLoS ONE 2015, 10, e0141560. [CrossRef] [PubMed]

37. Ippolito, J.A.; Cui, L.; Kammann, C.; Wrage-Mönnig, N.; Estavillo, J.M.; Fuertes-Mendizabal, T.; Cayuela, M.L.; Sigua, G.; Novak, J.; Spokas, K.; et al. Feedstock choice, pyrolysis temperature and type influence biochar characteristics: A comprehensive meta-data analysis review. Biochar 2020, 2, 421-438. [CrossRef]

38. Bruun, E.W.; Hauggaard-Nielsen, H.; Ibrahim, N.; Egsgaard, H.; Ambus, P.; Jensen, P.A.; Dam-Johansen, K. Influence of fast pyrolysis temperature on biochar labile fraction and short-term carbon loss in a loamy soil. Biomass-Bioenergy 2011, 35, 1182-1189. [CrossRef]

39. Sánchez-Monedero, M.A.; Cayuela, M.L.; Sánchez-García, M.; Vandecasteele, B.; D’Hose, T.; López, G.; Martínez-Gaitán, C.; Kuikman, P.J.; Sinicco, T.; Mondini, C. Agronomic Evaluation of Biochar, Compost and Biochar-Blended Compost across Different Cropping Systems: Perspective from the European Project FERTIPLUS. Agronomy 2019, 9, 225. [CrossRef]

40. Glaser, B.; Knorr, K.-H. Isotopic evidence for condensed aromatics from non-pyrogenic sources in soils-implications for current methods for quantifying soil black carbon. Rapid Commun. Mass Spectrom. 2008, 22, 935-942. [CrossRef]

41. Fischer, D.; Erben, G.; Dunst, G.; Glaser, B. Dynamics of labile and stable carbon and priming effects during composting of sludge and lop mixtures amended with low and high amounts of biochar. Waste Manag. 2018, 78, 880-893. [CrossRef]

42. Major, J. Biochar Application to a Colombian Savanna Oxisol: Fate and Effect on Soil Fertility, Crop Production, Nutrient Leaching and Soil Hydrology. Ph.D. Thesis, Cornell University, Ithaca, NY, USA, 2009.

43. Liu, J.; Schulz, H.; Brandl, S.; Miehtke, H.; Huwe, B.; Glaser, B. Short-term effect of biochar and compost on soil fertility and water status of a Dystric Cambisol in NE Germany under field conditions. J. Plant Nutr. Soil Sci. 2012, 175, 698-707. [CrossRef]

44. Zavalloni, C.; Alberti, G.; Biasiol, S.; Vedove, G.D.; Fornasier, F.; Liu, J.; Peressotti, A. Microbial mineralization of biochar and wheat straw mixture in soil: A short-term study. Appl. Soil Ecol. 2011, in press. [CrossRef]

45. Yu, Z.; Ling, L.; Singh, B.P.; Luo, Y.; Xu, J. Gain in carbon: Deciphering the abiotic and biotic mechanisms of biochar-induced negative priming effects in contrasting soils. Sci. Total Environ. 2020, 746, 141057. [CrossRef]

46. Naisse, C.; Girardin, C.; Lefevre, R.; Pozzi, A.; Maas, R.; Stark, A.; Rumpel, C. Effect of physical weathering on the carbon sequestration potential of biochars and hydrochars in soil. GCB Bioenergy 2014, 7, 488-496. [CrossRef]

47. Ventura, M.; Zhang, C.; Baldi, E.; Fornasier, F.; Sorrenti, G.; Panzacchi, P.; Tonon, G. Effect of biochar addition on soil respiration partitioning and root dynamics in an apple orchard. Eur. J. Soil Sci. 2013, 65, 186-195. [CrossRef] 